\title{
Semiotics Analysis of a Principal Character in Balem Hiwot Ande Ken
}

\author{
Lidiya Teka Gebremichael \\ Department of Ethiopian Language and Literature, Mizan-Tepi University, Mizan-Aman, Ethiopia
}

Email address:

lidiyateka@gmail.com

\section{To cite this article:}

Lidiya Teka Gebremichael. Semiotics Analysis of a Principal Character in Balem Hiwot Ande Ken. International Journal of Literature and Arts. Vol. 7, No. 3, 2019, pp. 61-65. doi: 10.11648/j.ijla.20190703.11

Received: May 13, 2019; Accepted: June 19, 2019; Published: July 2, 2019

\begin{abstract}
Analyzing a work of literature needs a sharp insight to understand beyond the written word. Meaning is more subjective than universal. Thereby, to extract meaning from creative work which can help to rewrite the work again by investigating the cultural connotations, signs, symbols and sayings (phrases) which embody the unsaid one. This is the reason that Semiotics is suitable to explore the features of meaning by considering everything as a sign. As the contemporary Semoticians there are three level of interpretation of sign. The first is recognizing or extracting the sign from the text which is syntactic, the second and the third is making meaning and analysing the Sign in relation to other sign which is semantic and Pragmatics. This article is intended to analyze the personality of the principal character of "Balem Hiwot Ande Ken" short story. Inter-textual method of analysis is implemented. The personality of Alem (principal character) is mainly related to her leg scar which is directly related to her sexual life. In the story the details of Alem's life not mentioned but there is some clues which lead us in to the secret of principal character that hide deep not to remember. Her life is miserable because of her sexual relationship with different males, mainly her scar and every action of her is symbolic to this.
\end{abstract}

Keywords: Semiotics, Sign, Scar, Identity, Sexuality and Life

\section{Introduction}

"Scars are just a treasure map for pain you've buried too deep to remember." [1]

Adame Reta is one of the best known authors in Ethiopia. He has written several short stories and novels since 1989 G.C. He is one of the best writers in the History of Ethiopian literature, especially in the genre of short story. He has his own consistent style in short story writing. Most of Adams work is constructed with different symbols. Those symbols are serving as a concrete to the text, as well as gives a space to the critics and the reader to form their own meanings on a text. On top of that, Adam has a quite different style in comparison to the other Ethiopian short story writers; the characters and the story itself are drawn from the life of ordinary people, who are not visible or a topic for most of the writers but they are a representatives for the life of the majority of the society. And again the style which he uses to present the narration also differs from the trend that is common in Ethiopian short stories.

Adam's first short story Book is called Mahalet, which is the name of a girl with the meaning of religious rhythm in traditional Ethiopian Orthodox Church and it has 10 short stories including the one I chose to analyze in this article which is entitled as Balem Hiwot Ande ken (one day in the life of Alem or it can be one day in the world's life).

The theory and method of analysis which I use to analyse the story is semiotics. Because the whole story of "Balem Hiwot Ande ken" is constructed with gestures, symbols, and movements. Moreover, the language he uses in his writing is irony, which needs an interpretation to reach into the meaning of the encoded messages. In general, most of Adam's writing is symbolic but I hadn't seen yet any analysis based on his work which figures out those symbolic codes.

\section{Methodology}

According Lois Tysion, Semiotics theory is basically similar to structuralism theory. However, there is a broad space of signifier in semiotics. Which Tysion briefly explain as follows,

Semiotics recognizes language as the most fundamental 
and important sign system. ... (Omissions is mine) structural linguistics, a linguistic sign is defined as a union of signifier (sound-image) and signified (concept to which the signifier refers). For semiotics, too, sign $=$ signifier + signified. However, as we just saw, semiotics expands the signifier to include objects, gestures, activities, sounds, images - in short, anything that can be perceived by the senses [2].

This indicates that, anything can be a sign if it has a meaning in the process of interpretation. Alike Tyson, most of Semoticians including Peirce and Eco believes that by the idea which says everything can be a sign. [3, 4] But nothing is a sign unless it interpreted as a sign. Thus, in the process of Semiosis or the process of meaning making, cultural convections and a shared knowledge is a key to produce the intended connotation. Danesi and Perrson and Chandler also identify culture as a major factor in producing and interpreting Sign $[5,6]$.

Those meanings are constructed based on how we interpret our world in relation to our values and practices, and make them comprehensible to others through representation and communicative structures [6]. Hence, sign has signifying and communicative functions.

Peirce sign notion has three components. What usually goes for a sign in everyday talk a representament. It is something that enters in relation with its object, which is the second component of sign. The third component of sign is interpretant. It is roughly speaking and sufficient for our purpose, close to what we would usually take as the sign's meaning. The interpretant mediates between the represeantamen and objects in such a way as to bring about an interrelation between them at the same time and in the same way it brings interrelation into itself with them [7].

Moreover, Peirce also theorized the three ways of signs represents objects which are icons, indexes and symbols. An icon is a sign that interrelates with its semiotics object by virtue of some resemblance or similarity with it. An index is a sign that interrelated with its semiotics object through some actual or physical or imagined casual connection. A symbol is somewhat more complicated, because it is arbitrary or purely convectional [7].

However, the interpretation of signs by their users can be seen from a semiotic perspective as having three levels, loosely related to C. W. Morris's framework for branches of semiotics.

As Daniel Chandler stated, the first level is Syntactic which represent recognition of signs in relation of other signs. Semantic and pragmatic are the second and the third levels of semiotic interpretation. These two levels are inseparable for some Semoticians, I agree with this argument because comprehension of the intended meaning of the sign (Semantic) and interpretation of the sign in terms of relevance, agreement... (Pragmatic), are parallel interpretational processes which we cannot do step by step as independent stages of meaning making [8].

The analysis of the article relay on the above three level of interpretation, identifying the sign, comprehending the meaning and interpreting the sign in relation to different cultural convections.

On the other hand Julia Kristeva, literary theorist who introduced inter-textuality, has described inter-textuality as a two way relation of text. The first is a text relation with the author and reader horizontally, and the second is a relation with other text vertically [8]. She asserts that "The concept of inter-textuality reminds us that each text exists in relation to others" [8].

To understand the principal character of Alem's personality in relation to her gesture, movements, facial expression, her leg scar, different acts and reactions analyzed through semiotics.

Thus, I used inter-textual analysis to write this article by making contextual relations with another short story from the author's work entitled Mahalet; this story is also found in same book with the story in which this analysis has been done ( the title of the book is derived from this story). And with the well-known Ethiopian writer BealuGirma's fiction entitled kademase Bashager (Beyond Horizon) wrote in 1970G. C.

\section{Result and Discussion}

\subsection{Syntactic}

The title Balem Hiwot Ande ken (one day in the life of Alem or it can be one day in worldly life), that one day has represents many things. The day can be one day in life of Alem (the main character) or it can be one simple day in worldly life. Whatever the case, that day is a sign of present, past and future for any individuals and for a whole world too. Even a single day is crucial to step on prints of curse or blessing, one day can change many things in a life.

The name of the principal character of Alem has double meaning in addition to its literal meaning (means world). In Ethiopian culture naming a child Alem is because of the thought that after having a child the meaning of life is completely turned into a different world. So a child means the whole world to most parents whom they live for or die for. On the other way, the word Alem has a meaning of pleasure by its connotation.

Alem is a countryside woman. She is a widow. Now she lives in the capital city Addis Ababa by selling different vegetables on the street. Tsedale is her friend, working with her in the road. In front of their work place, there is a man who is a Cobbler. The story starts and ends within one day, while Alem is gossiping to Tsedale about the shoe maker Asefa "Jibo"( Jibo is his nick name meaning ' hyena'); we don't know why Alem calls Asefa by this name, but it is culturally connotes a cruel and gluttonous person)

"Look Tsedale!, I think he saw a donkey he start howling"

"Please leave it! What did he done to you"

"I hate him, look at him" [9].

But she has a sexual relationship with him. She is trying to hide her affair with him. At the first page of the story the narrator described Alem in one sentence in a quite weird way "her head bears her body below the waist" [9]. It seems 
paradox, because it is our neck and other part of our body which carries our head. This was the way we learn about our body structure. These create some questions, such as, what is wrong with her body below the waist? Is there something there which the author won't tell us about Alem? Has it a relationship with her life?

There is big part of our body below our waist, which is our leg. Alem has a scar on her right leg which makes her unstable. The narrator describes her scar like this "Alem stood up from her sitting, stretching her leg. In her leg, there is long and thin scar, it makes her lame. When she saw her right leg, she hates herself. She can't sit for long; therefore she stands up frequently and stretches herself. Because of this, village kids insult her by saying "shenkilili" (it's an insult that means limp or disabled)" [9]. However, her leg able to carries her head.

Alem's leg is the symbol of her life and personality. To hide the real identity of herself, she uses her head (mostly related to mind) to persuade peoples about how kind and beautiful she is. She is smart to use her mind to cover her miserable life. This is the reason why the narrator says "her head carries her body below her waist". [9]

Sigmund Freud said about the symbol of the legs "The foot is an age-old sexual symbol which occurs even in mythology" [10].

In this short story we don't find out any details about Alem and her former husband. She doesn't want to talk about the details about her past life. Sometimes she talks to Tsedale a little without considering it as a serious issue. Those spontaneous talks of Alem give us a little clue about her past. While she is talking about her life, she stands and stretches her leg; she feels pain and sees her leg scar. Because it reminds her what causes her to divorce: her unfaithfulness.

Alem talks to Tsedale about her husband. She tells her that she left her husband. But she didn't mention why she left him. And she told to Tsedale that her husband married another woman and had children. (When she talks of this, her face reflects her remorse and jealousy). Despite this, Alem ends up sleeping with her former husband on a visit to her home town after he has re-married and had children.

Not only that, Alem herself told Tsedale that when she was at her aunts home when she came to Addis Ababa after divorcing her husband, within a month she slept with her aunt's husband and their driver. She isn't ashamed by this errant act of hers. Every day when Alem sees her scar in her leg, she remembers that one day in her life makes her a widow. She regrets what she did to her husband. Then when she thinks of that, she starts looking someone to sleep with again and again. Because this is the only option she has to keep her mind at peace, at least for a while.

Usually, body scars remind us something of awful in relation to the accident where we got it. A scar is a "mark of indentation resulting from damage or wear or a last in moral or emotional injury" [11]. In most culture, a scar is a symbol of terrible things that happened in the past. It is the same in Ethiopia. Because of this, most of the time people try to cover their scar with clothes or hair, unless it occurs at the centre of their face.

In another short story that is found at the same book titled Mahalet, the principal character named Mahalet has a scar on the left of her forehead. Mostly she tries to cover it by her hair.

It was at night, she was serving supper for her bachelor employer, he starts struggling with her, to rape her; meanwhile, the spoons in her hand fall and hurt her forehead. Finally, he raped her as he wishes. This was how her scar happens. When she sees it, it reminds her of that bad day which makes her life miserable. To hide that horrible memory, she usually uses her hair as a cover [9].

In one of the well-known writers Bealu's fiction entitled Kademas Bashager, the principal character Abera has a scar on his chest. It happened in his childhood when he was seduced by his parent's servant. The servant, Tringo, had a boyfriend; when Abera's mother went for coffee to their neighbours, Tringo ran to her boyfriend Buykedagn to have sex with him. When Abera saw the two, he began to burn with jealousy. Because Tringo and Abera were also in a sexual relationship [12].

As usual, one day the mother of Abera went out for coffee; immediately Tringo and Abera start to seduce each other suddenly his mother comes back home to get her coffee cup which she has forgotten. They jumped from the "medeb" (a traditional bed made by mud mostly used in rural areas of Ethiopia) for they were frightened and trying to hide from his mother. Abera fall onto the knife which was on the floor.

In his adulthood when he sees the scar on his chest it reminds him of Tringo and his jealous character. And it is a symbol of his envious personality throughout his life. He ends up in jail for life, because of murdering an innocent man who he suspects is sleeping with his girlfriend [12].

In general a scar or scratch mark is not a simple accidental element when it is found on a characters body. Most of the time, it is a sign of a characters personality, or awful past life or bad memory which leads them into a tragic or miserable life.

This is why Alem is ashamed of her leg scar because it reminds her about past. She don't want to think about it, when she see her scar, she feels pain; she immediately stands and stretches her leg. To repress her feeling of guilt and shame on herself, then she starts talking about Jibo to her friend Tsedale as if she doesn't want him; she does this deliberately to make herself not to think about her past.

\subsection{Semantic and Pragmatic}

Callavaro said "Signs do not embody specific meanings or concepts. Rather, they give us clues which only lead to meanings through interpretation." [13]. According to this, Alem's scar and other gestures of hers is a sign which gives us a hint about Alem's personality and her life in general.

Kinesics is the study of body movement, gesture and posture. Posture is a rich channel for conveying non-verbal communication. The way we walk, talk, stand, and sit closeness posture is concerned with interpersonal attitude like: friendliness, hostility, superiority of inferiority, and also 
indicate emotional state like the degree of tension or relation [14].

So through interpretation we can reach the meaning which is embodied in Alem's scar in general and in her movements and gestures specifically.

There is a hidden truth in to Alem's scar; a parts of the body where a scar is happened which is her leg is the symbol of sexuality. Thus, we can perceive that Alem's past is determined by her sexual life. She divorces her husband because of her unfaithful act. Though we don't know how the story of the scar happens, we can be sure that it was somehow related with that day that brings a consequence of divorce. When she sees her scar she regrets about her past; she tries to escape from her guilt, that's why often she performs the same sexual act.

And she gave up on life, so she has sex with anybody. But she pretends in front of her friend Tsedale when she asks her about Asefa and her relationship.

"You know well how much I hate him; even I do not have greetings with him. They thought that you are a stranger for me that why they are trying to gossip me. "... I know. I know well (Alem said this when Tsedale told her whose talking about her and Asefa) she is jealousy of me when I became successful. Since our childhood when even we were playing with mud she was my enemy." [9]. But she is lying; she is trying to convince her friend to consider her as decent women.

The narrator described Alem's action, by saying that 'she stretches her head, like a dog'. In Ethiopian culture comparing a human with a dog is the most insulting thing. Dogs are the symbol of cur and disgusting acts. Alem doesn't like her character of adultery, but she can't stop it. After divorcing her husband, she gave up on herself, that's why she slept with different men (with her aunt's husband and their driver and now with Jibo) without any hesitation. Gradually her needs increased and she did it with anybody to forget her past. In Amharic language there is a saying "the wet person doesn't fear rain". This is what happens in her life, she already lost her dignity.

But she doesn't want to expose herself to critics and defends herself by telling them about her beauty, kindness, generosity etc. However, sometimes her real identity is revealed through her unconscious speech.

Alem touched the potatoes - with her fingers and she looks on the potatoes in unstable way as if her past was lost in the middle of the potatoes.

She said to Tsedale by hold up her neck, "if I can do a magic" ---as if her eyes filled with lights.

... (Omissions are mine)

"What will you do if you can make a magic"

"I would make a magic to those potatoes to turn them into many rich husbands.

Not only rich also kind,

Not only kind also handsome,

..Not only handsome also healthy..." [9].

She won't stay with one man, and she need many husbands equipped with all good things. This is impossible.
At the same time, she doesn't want to live like how she lives now. She regrets and wishes to live like her friend Tsedale by having a husband and children. But she can't. Something inside herself pushes her to escape from this kind of social norm to live as she wishes and to have a freedom to go with anybody. She said to Tsedale while she starts prepare to go to her husband and children.

I am kind thats why people come in to my life...woo I make you delay, it gets dark. You have children. You are not like me-so crying children.

You know what, I can't live with children. If I have I will kill them and

I enjoy with that driver the one I told you about.

Even why not with the shoe worker [9].

Now suddenly without consciously doing Alem has told Tsedale how she really thinks of life. Tsedale is frightened when she hears what Alem says, the idea of killing the child is unbelievable to her. Because she knows the experience of motherhood and d how much it costs.

Surprisingly, in spite of everything what she said Alem was trying to pretend as if she is innocent. However, her unconscious mind made her reveal her real identity. She won't submit to the society's marriage norm, looking after the children is intolerable for her.

Because of this deviance, her marriage has failed. She knows what they think about her, but she doesn't care and she doesn't give a shit about what they say to her. Nevertheless, she uses her mind to tell her friend what she is, before she tells what she heard from others about her. This is why the narrator said "her head carries her body below her waist" [9]. She understood that whatsoever the fact how self esteem can influence the image of a person in front of others.

In addition, Alems gestures are symbolically erotic. She is sitting the whole day by displaying her thigh to the direction of "Jibo" (shoe maker). She tries to flirt with him the whole day with her eyes. They communicate and make an appointment for the night without talking a word.

Eye contact, an important channel of interpersonal communication, regulates the flow of communication. Furthermore, eye contact with audience increases the speakers" credibility. How often and long we meet other people's eyes is a way of sending very important message about relation. One of the most potent elements in body language is eye behavior [15].

In Ethiopian culture wearing a piece of clothing that exposes the thigh is considered a sexual invitation, especially in rural areas, which Alem comes from. When the girl sits by exposing her thigh, she is considered as rude and a kind of harlot. Thus, Alem's unfaithfulness leads her into that one day mistake which makes her deviance to the norm of the society once for all. But she doesn't want to give her hand to the critics, she is trying to defend herself by acting as if she is innocent and a proud women.

..."See how he is staring at you, this shoe maker" said Tsedale... [9] (Omissions are mine)

"You see? He thinks he can take me easily while the nights come. As if moon, darkness, stars push me out of home. I am 
not hyena like him. I will not sleep with that kind of guy. I thought that all his body is like a hammer. I don't know the hammer in my childhood. I grew up with milk and honey. Is he considering me as his customers whom he deceived with his promise to make a shoe for them? Why not he keeps quiet and just biting his nail?

"Oh! You hate him this much"

... (Some dialogue omitted here)

"He considers me something like - a whore. Even if I am whore, I didn't do with the shoe maker. I prefer to die...... woo it getting dark" [9].

In contrary, all of her action is purposefully planned to seduce Asefa. This is why I am saying her gestures are also signs of her sexual invitation to anyone she meets. It makes her lonely and a wanderer in her life. Moreover, this becomes her identified personality among the society, even in front of her friend Tsedale.

However hard she tries, Alem couldn't be able to pretend to her friend Tsedale about her personality, she knows her well. But she couldn't dare to tell the truth to her directly. However, she tells to Alem how everybody thinks about her relationship with Jibo.

"Do you hear me Alem? People said all of your shoes are his gift"

"They can say. I have my own. I have money I can buy .... Tsedale it gets dark for you"

.... (Omissions mine)

While Tsedale is crossing the river when she gives a good bye greeting to Alem.

"Alem good night! And be careful" said by looking in the direction of shoe maker

Alem saw Tsedale and smiled. And put her finger in her mouth to say be quiet Jibo will hear us [9].

Now the day is over, Tsedale has gone to her home. Immediately, Alem called "Jibo" said "why you are staring at me the whole day? Are you trying to expose our relationship to the people? If you need that we can stop, come tonight at 7 o'clock and bring the shoe with you that you promised to give me"

"Ok Madam"

They have gone to different direction [9].

To hide their relationship they always go to in different direction to their home. It is the same that they have different pain, wishes and need in their life. But to night they become one by forgetting all those differences.

\section{Conclusion}

As a theory, semiotics is mainly focused extracting symbols that encode different meanings which relate with cultural definitions in once society. Most of the Semoticians were from the linguistic, but semiotics theory also suitable for literature, folklore and different art works.

In my analysis the principle character Alem has many hidden story and she is trying to cover it by over acting about herself. The narrator also doesn't tell us anything ahead of her speech but there is a clue on the story about her past and identity. It is mainly her leg Scar which embodied her identity which is the symbol of her wanderer character that makes her lonely, divorced and unhappy women.

\section{Acknowledgements}

I would like to give many thanks for almighty God for he gives me strength in every work of my life.

I also like to thank my dear husband kassahun for your encouragement and constructive comments.

Thirdly my sincerely thanks goes to my colleagues Gezachew Nemomesa, Mesfin Wedajo, Bezualem Amelak, and Getahun Kassa without your encouragement and support this article wouldn't be successful as it is.

\section{References}

[1] Jodi Picoult. (2012). Lone Wolf. Published by Atria/Emily Bestler Books.

[2] Tyson, Lois. (2006). Critical Theory Today: User-Friendly Guide. Imprint of Taylor and Francis Group, an informal business.

[3] Peirce, C. S. (1931-57) Collected papers 1931-1957 (71b/s), Harvard. Cambridge: University Press.

[4] Eco, U. (1976). A Theory of Semiotics. Bloomington: Indiana University Press.

[5] Danesi, M. and Perron, P. (1999). Analyzing Cultures: An Introduction and Handbook. Bloomington: Indiana UP.

[6] Chandler, D. (2003). Semiotics for Beginner. (Www document) URL http//wwwaberac.uk/media/document/S4B.119/2000.

[7] Paul cobley. (2005). The Rout ledge Companion to Semiotics and Linguistics. London and New York, Taylor and Francis Group.

[8] Chandler Daniel. (2007). Semiotics the Basics. New York, Published in the Taylor \& Francis e-Library.

[9] Adame Reta. 1989. Mahalet. Addis Ababa, kuraze publishing.

[10] Tewodrose Gebre. (2010). Myth and Sexuality:A Mythopoeic Reading of Letum Aynegallin. Callaloo, Vol 33, No. 1, pp 136145.

[11] "Scar". (2014). Encyclopcedia Britannica. Encyclopædia Britannica Ultimate Reference Suite. Chicago: Encyclopædia Britannica.

[12] Bealu Girma. 1970. kademas Bashager. Addis Ababa, Ethiopian book Institute.

[13] Cavallaro, Dani. (2001). Critical and Cultural Theory. London: The Althlone Press.

[14] Fiske, J. (1972). Introduction to Communication Studies. USA: Methuen, Inc.

[15] Brooks, William. 1977. Speech Communication. USA: Proum Company. 